\title{
AC 2011-2323: EXPERIENCES OF SCHOLARS IN THE REINVIGORAT- ING ENGINEERING AND CHANGING HISTORY PROGRAM: A CASE STUDY OF THE FIRST GRADUATE STUDENT COHORT
}

\author{
Jiabin Zhu, Purdue University, West Lafayette
}

Jiabin Zhu is a Ph.D. student in the School of Engineering Education at Purdue University. She obtained a B.S. in Physics from East China Normal University, a M.S. in Optics from Chinese Academy of Sciences (CAS), and a second M.S. in Biomedical Engineering from Purdue University. Her primary research interests relate to comparative study methods and frameworks in engineering education, global engineering, professional development and mentoring of engineering graduate students. She is a student member of American Society for Engineering Education (ASEE).

\section{Dr. Monica Farmer Cox, Purdue University, West Lafayette}

Monica F. Cox, Ph.D., is an Assistant Professor in the School of Engineering Education at Purdue University. She obtained a B.S. in mathematics from Spelman College, a M.S. in industrial engineering from the University of Alabama, and a Ph.D. in Leadership and Policy Studies from Peabody College of Vanderbilt University. Teaching interests relate to the professional development of graduate engineering students and to leadership, policy, and change in science, technology, engineering, and mathematics education. Primary research projects explore the preparation of engineering doctoral students for careers in academia and industry and the development of engineering education assessment tools. She is a NSF Faculty Early Career (CAREER) award winner and is a recipient of a Presidential Early Career Award for Scientists and Engineers (PECASE).

\section{Demetra Evangelou, Purdue University, West Lafayette}

Dr. Demetra Evangelou is Assistant Professor of Engineering Education in the School of Engineering Education at Purdue University. She has a PhD in Early Childhood Education from the University of Illinois at Urbana-Champaign and international expertise in early childhood policy and research methods. Her current research focuses on developmental engineering, early education antecedents of engineering thinking, developmental factors in engineering pedagogy, technological literacy and human-artifact interactions. She is a member of Sigma Xi Science Honor Society and in 2009 he was awarded the prestigious NSF CAREER Award.

\section{Cyndi Lynch, Purdue University, West Lafayette}

Cyndi Lynch is the Director of Fellowships and Graduate Student Professional Development for the Purdue Graduate School. Cyndi administers the Univeristy fellowship program and directs the professional development program for graduate students.

\section{Audeen W. Fentiman, Purdue University, West Lafayette}

Audeen Fentiman is Associate Dean of Engineering for Graduate Education and a Professor of Nuclear Engineering at Purdue University.

\section{Phillip S Dunston, Purdue University}

Phillip S. Dunston, Ph.D., is an Associate Professor in the School of Civil Engineering at Purdue University. A past NSF Faculty Early Career (CAREER) award winner, he obtained his degrees (B.S., M.S., and Ph.D.) in civil engineering from North Carolina State University and then served on the Civil and Environmental Engineering faculty at the University of Washington before moving to Purdue. His primary area of research involves the application of Virtual Reality technologies to design processes, construction tasks, and workforce training. Concurrently, he has participated in activities to stimulate the pipeline of minority students pursuing higher education in engineering. 


\title{
Experiences of Scholars in the Reinvigorating Engineering and Changing History Program: A Case Study of the First Graduate Student Cohort
}

\begin{abstract}
The focus of this paper lies in the understanding of the experiences of five scholars from underrepresented groups in the Reinvigorating Engineering and Changing History (REACH) Program using a case study framework. Fieldnotes of the REACH scholars' activities and meetings and one-on-one interviews with REACH scholars were the main data sources to understand scholars' experiences in the REACH program. Their experiences include transitioning from undergraduate to graduate school, mentoring through and outside of the REACH program, and professional development trajectories. Findings from our case-by-case analyses offer a unique perspective on the challenges in their transitioning from undergraduate programs to graduate engineering programs, their mentoring experiences throughout the first year of graduate school and the different supports they received from REACH or other programs. The findings on the scholars' experiences provide direct feedback for the REACH program and also inform our next steps in the evaluation effort. Moreover, implications from this study offer practical suggestions for the transitioning from undergraduate to graduate programs and the development of mentoring support for graduate students.
\end{abstract}

\section{Introduction}

Most domestic engineering graduate students faced multiple challenges when they were first enrolled in graduate programs ${ }^{1}$. External challenges could include difficulty in their socialization process or mismatch of interests in research or future career options ${ }^{1-2}$. Brown suggested additional challenges facing minority and underrepresented students, such as the lack of funding that prolongs their time to degree completion ${ }^{3}$. Other challenges include the absence of mentoring support and social connections. The benefit of mentoring in helping underrepresented students to prepare for academic careers and to overcome extra barriers in cultural adjustment is discussed by multiple experts ${ }^{3-6}$.

To address some of these challenges, the Reinvigorating Engineering and Changing History (REACH) Scholars Program was developed at a Midwestern University to offer domestic graduate students (including qualified Master's and direct Ph.D.s) with research experiences in engineering and with comprehensive professional development experiences outside of their home departments. Informed from research, the REACH program uses a multiple apprenticeship framework to recreate intellectual and psychosocial linkages between graduate students and faculty members through the implementation of the following five tenets: intentionality; multiple relationships; collective responsibility; recognition; and respect, trust, and reciprocity ${ }^{7}$. Such mentoring aims to help students to transition from undergraduate engineering, science, and math programs to graduate engineering programs. It complements traditional experiences of graduate students, exposes students to career opportunities in and out of academia, and makes students aware of multidisciplinary and global opportunities available to them after graduation. 


\section{Project Rationale}

There have been multiple organizations and programs serving underrepresented and minority students in the Midwest, such as, the National Science Foundation's Louis Stokes Alliances for Minority Participation (LSAMP) Indiana and the Midwest Crossroads Alliance for Graduate Education and the Professoriate (AGEP) program. LSAMP Indiana is an alliance of eight Indiana universities with programs of support that target underrepresented STEM students. The Midwest Crossroads AGEP program is a companion program of support at the graduate level.

Organizations and programs like these provide early research experiences for undergraduate students, mentoring opportunities, and interaction opportunities with faculty members.

Informed from research, the REACH program uses a multiple apprenticeship model consisting of five features (intentionality; multiple relationships; collective responsibility; recognition; and respect, trust, and reciprocity) ${ }^{7}$. In the REACH program, mentors introduce Scholars to the academic engineering community and provide them with a variety of perspectives to help them succeed as Scholars. Some activities in the REACH community include: students meeting, professional development workshops and seminars, developing mentoring networks, scholars serving as mentors, and the sharing of academic resources.

Besides these activities, several other characteristics make the REACH program unique in its roles of serving minority and underrepresented students. First, the REACH program draws upon the diverse backgrounds, expertise and the experiences of the PI team, with perspectives from various levels and disciplines in the Graduate School and the College of Engineering. The exposure to different perspectives in the administration of the program provides the Scholars with opportunities to engage people outside of their home departments. Finally, the program has the potential to serve as a model for other graduate programs that are trying to engage their Masters and Ph.D. students in cohort experiences during their graduate careers. Via REACH assessment efforts, benefits of such experiences might be identified for first-time graduate students.

This paper presents information on the assessment efforts based on field observations of the interactions of Scholars and mentors at REACH meetings and on activities and one-on-one interviews with scholars. To explore the Scholars' experiences in their transitions to graduate schools and within the REACH program, we prepared the following research questions to guide both the interview process and data analysis:

1. What are the challenges during the transition from undergraduate to graduate school for REACH Scholars?

2. What are the benefits Scholars obtained from participating in the REACH program?

3. What are the mentoring supports they obtained or hope to obtain?

\section{Methods}

\section{Participants}

Five scholars from underrepresented groups were our participants and were members of the first cohort of Scholars. A member of the assessment team observed their meetings and activities over the first one and half years of the program. Appropriate Institutional Review Board documents 
were submitted and approved. Table 1 shows the basic information of our participants. The participants' names were changed, and pseudonyms that made the gender obvious were used.

\begin{tabular}{|c|c|}
\hline Name* & $\begin{array}{l}\text { Wants to Obtain a Ph.D. } \\
(\mathrm{Y} / \mathrm{N})\end{array}$ \\
\hline Dan & $\mathrm{N}$ \\
\hline Edward & $\mathrm{N}$ \\
\hline Debora & Y \\
\hline Jenny & $\mathrm{N}$ \\
\hline Nancy & Y \\
\hline
\end{tabular}

Table 1. Participants’ basic information. * Pseudonyms

\section{Data}

Fieldnotes of the REACH scholars' activities and meetings and one-on-one interviews with REACH scholars were the main data sources. A researcher kept regular fieldnotes on REACH scholars' activities and meetings. Researchers' reflective notes were also summarized after meetings and activities. One-on-one interviews were conducted and recorded with the consent of the participants. The students were not compensated for their participation in the study. There were ten different questions in our interview protocol concerning the different aspects of our studies including: 1) their experiences of transitioning into graduate school, 2) their REACH experiences and 3) their mentoring experiences. Sample interview questions are as follows,

- How would you describe your graduate student life?

- How would you describe your REACH experiences?

\section{Coding}

Fieldnotes were transcribed after each meeting and activities. One-on-one interviews were transcribed. After the transcription, transcripts were revised where all potential identifiers were substituted with placeholders to protect the scholars’ identities. Qualitative data analysis was performed to extract the themes and trends of our data. A brief description of qualitative data analysis procedures is described as follows.

Prior to qualitative data analysis, all data were read and re-read to make a general good sense. Researcher kept reflective notes throughout the reading process. After the initial reading of data, interview transcripts were analyzed by first grouping the transcripts into text segments. Secondly, the researcher divided the text segments into smaller text segments representing at least one or more ideas. The researcher then interpreted the meaning of these text segments and labeled them with descriptive codes (open-coding) ${ }^{8-9}$. These codes were grouped into larger categories representing similar ideas. Guided by our research questions, three large categories here are: challenge during transition; the REACH experience; and mentoring.

\section{Case analysis}


Case analysis has been identified to be beneficial for the understanding of individual experience in depth ${ }^{10}$. Because the participants in this study possessed diverse backgrounds, individualized experiences and developmental trajectories, case analysis allowed the researchers to capture their individual challenges and experiences with the REACH program and of graduate studies.

\section{Results}

Our participants went through the first one and half years together as a cohort. They demonstrated some common experiences and individualized experiences and perceptions. These perceptions and experiences are organized in a case-by-case format as follows.

\section{Dan}

Dan initially experienced adjustment difficulties due to his lack of contact with fellow students and faculty members at the beginning of the graduate studies. He said,

"It's definitely a big adjustment for me coming from [place]. I'm a master's student in engineering and it's tough, of course. Initially I had some issues trying to meet the right contacts and meet the right people to help me better my experience."

But as indicated by Dan, after a few weeks, he started to find connections on campus. By the end of his first year; he actually grew into a leader in a campus-wide students' group. He credited a lot of his growth to the connections and help from REACH experiences. He said,

"The people that really are like me and are really trying and striving to be successful as I am, and to have the appropriate mentors and faculty that really are there when we need them and support us."

"If we have any question about funding to travel, or going to conferences, or to help other students, or things like that...they're there for us. To be by our sides to guide us, you can't ask for any more."

\section{Edward}

Edward initially showed interested in research; however, he encountered difficulties in communicating with people in his department. He described his experiences with this process during the interview:

"As far as research is concerned, earlier on, or during last semester I was really geared to do research. And I contacted someone and I thought that it was pretty much set. I tried to contact them again and again, wasn't getting replies back, and I have a huge pet peeve on like responding to emails. I like hate to be inconvenienced. So when I tried, I'm only going to try so many times. I tried, it didn't work out. I say, 'Well I'm here. I'm on a non-thesis track anyway, so research isn't my primary focus. ',

Edward then shifted his interests and found a part-time job in a law firm to pursue his other interest in technical patent laws. He also demonstrated great interest in study-abroad programs. He mentioned, 
"I'm really big into study abroad now. I'm trying to get as much international experience. So I have gone to [country name]; I went there in [time]. I'm going to [country] in [time], and hopefully before I graduate next spring, I can knock out at least two more."

Edward also benefited from the REACH program in terms of making connections and mentoring.

"The REACH program was a good start because I didn't know anybody outside of my friend, [name]. So we met some other students. [Mentor name] and [mentor name] have been great, great, great mentors as far as helping me to reach out to other people."

\section{Debora}

With a clear intention to pursue a Ph.D. degree, Debora showed a lot of initiative and demonstrated the strongest academic performance among the participants. Although a direct Ph.D., she came with prior industrial experiences and had connections with professors in this institution prior to the start of her graduate study. Even so, she still experienced challenges during the transition, especially in terms of work-life balance. She said,

"So, it's been a little overwhelming, graduate student life. It feels like I've had to sacrifice a lot of what I traditionally would enjoy in terms of recreation. And that's totally typical right? So there've been sort of frustrations associated with that."

Now Debora is very involved in research and professional activities because of her connections. She is involved in projects, some campus organizations, and professional conferences. Although originally she felt intimidated about the idea of getting a Ph.D., these involvements strengthened her intent to pursue a Ph.D. degree. By the time she was interviewed after a year and a half in the REACH program, she expressed a strong commitment to obtaining her Ph.D. degree.

\section{Jenny}

Jenny expressed that her main challenges over transition came from time management and course work. She mentioned that,

"Honestly, it really requires you to be on schedule and really good time management. It's busy, but I'm learning a lot and yeah, it's moving fast."

"You can get caught up in just your classes and your everyday life so you don't really get the chance to interact or look outside of your program."

As far as mentoring experiences, she believed that to have someone who is ready to help and guide you by providing the insights into different available options is of great importance. She said:

"[I would like] someone who has the time and the patience to work with someone. Because there are mentors who are they're really good in their field, and they're good at what they do, but sometimes they just don't have the time or the patience to work with different students." 
Beside the readiness to help, she also suggested that personal match of work ethics was very important in the development of a collegial relationship.

\section{Nancy}

Nancy tended to be quiet in most meetings and took notes instead of taking initiatives. She also expressed her lack of taking initiative during the interview process.

"She [advisor] was saying that as a doctoral student you tend to just take more initiative than a Master's student. I'm used to someone saying, 'Okay, I have this project, I'd like you to do this.'”

As she transitioned to graduate studies, she faced choices in research at the time when she needed to take a qualifying exam. In one of the REACH meetings, she mentioned that at the time of qualifying exam she really needed to find out what her research interests were. As a result of this and connections with REACH mentors, she explored her potential interests in other programs. She also made some attempts to communicate with professors in other departments. We observed the development of her academic abilities and growth in professional skills.

\section{Discussion}

Most of participants experienced some types of challenges over the transitions to graduate education. Some common challenges include difficulties in time management or balance between work and life, lack of connections, and the large amount of course work. As students came directly from undergraduate programs or after working in industry (one of our participants), they experienced more difficulties than students who had a master's degree at the time who came to this institution. These challenges were also observed at the first couple of REACH meetings. A lot of the meeting time was devoted to course-related questions or experiences. For example, one student asked, "Is it necessary to take this course? But, I am the only first-year student in the class."

Besides challenges in coursework, most of the students agreed that they experienced a lack of connections at the beginning (except Debora). Three of them came from a much smaller university than this current institution. Also, their original universities usually had strong ethnic group supports in which they could engage. These observations suggest that although there are orientations designed to help graduate students make a smooth transition, the transitional difficulties are still present for these underrepresented students especially in making initial connections academically and socially.

For their REACH experiences, scholars regarded the "people" element as the most important component of the REACH program. Most of them valued that they were comfortable expressing their ideas and concerns in REACH meetings and activities. Most scholars identified "readiness to help" as one of the key characteristics of an academic mentor. Most of our scholars found this characteristic to be true in REACH mentors. Being approachable and accessible has been identified as one of the main characteristics of effective instructors by multiple researchers ${ }^{11-12}$. Here, we found our scholars expressed similar concerns in the approvability and accessibility of 
an academic mentor. This finding suggests that having academic excellence and being approachable are the two indispensible aspects of a good academic mentor.

\section{Conclusions}

The REACH program aims at building an intellectual psychosocial linkage between graduate students and faculty members and creating a scholarly community. For the experiences of the first cohort, the REACH program demonstrated different strengths in building such a community. Recognized by our students, REACH mentors showed the intentionality and readiness to help students. By knowing that these mentors care about their progress and are willing to provide help, REACH scholars experienced some growth in both intellectual and social aspects. We did observe some frustrations in their research experiences and course studies, which were out of the immediate control of members of the program. These observations suggested that a smooth transition for graduate students requires collaborations from multiple stakeholders, including professors, administrators, senior graduate students, staff and other related members in a scholarly community.

\section{Acknowledgement}

This material is based upon work supported by the National Science Foundation under Grant No. 0850199.

\section{Bibliography}

1. Golde, C. M. (1998). Beginning graduate school: Explaining first-year doctoral attrition. In M. S. Anderson (Ed.), The experience of being in graduate school: An exploration. New Directions for Higher Education, No. 101. San Francisco: Jossey-Bass.

2. Lovitts, B. "Leaving the Ivory Tower: A Sociological Analysis of the Causes of Departure from Doctoral Study." Doctoral dissertation, University of Maryland, 1996.

3. Brown, S. V. (2000). The preparation of minorities for academic careers in science and engineering. In G. Campbell, R. Denes, \& C. Morrison (Eds.), Access denied: Race, ethnicity, and the scientific enterprise (pp. 239268). New York: Oxford University Press.

4. Redmond, S. P. (1990). Mentoring and Cultural Diversity in Academic Settings. American Behavioral Scientist, 34(2), 188-200.

5. Hill, R. D., Castillo, L. G., Ngu, L. Q., \& Pepion, K. (1999). Mentoring Ethnic Minority Students for Careers in Academia: The WICHE Doctoral Scholars Program. The Counseling Psychologist, 27(6), 827-845.

6. Lamb, S. (1999). The Holmes Scholars Network: A Networking Mentoring Program of the Holmes Partnership. Peabody Journal of Education, 74(2), 150-162.

7. Walker, G.E., Golde, C.M., Jones, L., Bueschel, A.C., \& Hutchins, P. (2008). The Formation of scholars: Rethinking doctoral education for the twenty-first century. San Francisco: Jossey-Bass.

8. Patton, M. Q. (2002). Qualitative research and evaluation methods (3rd ed.). London: Sage Publications. 9. Creswell, J. W. (2003). Research Design. London: Sage Publications.

10. Stake, R.E. 1995. The art of case study research. Thousand Oaks, CA: Sage.

11. Cox, MF, Zhu, J, Cekic, O, Chavela, R, \& London, J. (2010), Knowledge or Feelings: First-Year Students' Perceptions of Graduate Teaching Assistants in Engineering, Journal of Faculty Development, 24, $27-34$. 12. Gall, K., Knight, D., Carlson, L., \& Sullivan, J. (2003). Making the grade with students: The case for accessibility. Journal of Engineering Education, 92(4), 337-344. 